\title{
Metformin treatment in NIDDM patients with mild renal impairment
}

\author{
Vincent Connolly, Colin M Kesson
}

\begin{abstract}
Summary
Metformin is contraindicated in patients with renal failure because of the risk of lactic acidosis. This study assessed the complications of metformin treatment in patients with non-insulin-dependent diabetes mellitis with normal and raised serum creatinine. Subjects using metformin with serum creatinine above the upper reference range $(120 \mu \mathrm{mol} / \mathrm{l})$ were identified $(n=17)$ from a hospital diabetes register; those with abnormal liver function, cardiac failure, peripheral vascular disease or recent severe illness were excluded. Reference plasma lactate levels were established, mean $1.742 \mu \mathrm{mol} / 1$ (SD 0.819) using age-matched non-diabetic subjects. Age-matched patients treated with metformin with normal serum creatinine levels formed the control group $(n=24)$. Details of gastrointestinal disturbance were recorded, and plasma lactic acid and vitamin B12 levels measured.

The median total daily dose of metformin in both groups was $1700 \mathrm{mg}$. The mean plasma lactate in subjects with serum creatinine 80-120 $\mu \mathrm{mol} / \mathrm{l}$ (2.640 mmol/l (SD 1.434) $\mathrm{p}<0.02$ ) was higher than non-diabetic control levels while diabetic subjects with serum creatinine 120-160 $\mu \mathrm{mol} / /$ had a mean of $2.272 \mathrm{mmol} / \mathrm{l}$ (SD 0.763) $\mathrm{p}<0.05$. There was no significant difference between the two groups taking metformin, nor any significant difference in the reporting of gastrointestinal symptoms between the groups on metformin ( $11.76 \%$ vs $12.5 \%)$.

Plasma lactic acid levels are higher in diabetic subjects taking metformin compared with healthy volunteers but, within the diabetic groups, the small elevation of serum creatinine was not associated with higher plasma lactate levels.
\end{abstract}

The Diabetes Centre, The Victoria Infirmary NHS Trust, Langside

Road, Glasgow G42 9TY, UK

V Connolly

CM Kesson

Correspondence to

Dr Vincent Connolly,

Senior Registrar, Diabetes

Care Centre, Middlesbrough

General Hospital, Ayresome

Green Lane, Middlesbrough,

Cleveland TS5 5AZ, UK

Accepted 13 November 1995 effect, ${ }^{3,4}$ reducing fasting blood glucose levels ${ }^{5}$ without causing hypoglycaemia. ${ }^{6}$ Furthermore, beneficial properties are noted in terms of
Biguanides were first introduced for the phenformin in $1976,{ }^{1,2}$ but presentation of metformin continued. The benefits of metformin use are related to its antihyperglycaemic weight reduction, ${ }^{7-9}$ reduction of triglyceride and cholesterol levels, ${ }^{10}$ increased fibrinolytic activity, ${ }^{11,12}$ reduction in plasminogen activator inhibitor, ${ }^{13,14}$ without an increase in peripheral insulin levels. ${ }^{15}$ All of these beneficial effects confirm the efficacy of metformin, particularly in obese subjects with type 2 diabetes. However, metformin-like phenformin has been implicated in the causation of lactic acidosis and this has been associated with renal impairment, which reduces the clearance of metformin. This has led to the practice of avoiding metformin in renal impairment. A clear cut-off point has not been defined, although a serum creatinine $>120 \mu \mathrm{mol} / 1$ has been suggested. ${ }^{16} \mathrm{We}$ conducted a case-control study of NIDDM patients taking metformin to determine the effects of modest elevations of serum creatinine on plasma lactic acid levels, compared with normal levels.

\section{Materials and methods}

Patients on metformin with serum creatinine above the upper limit of the reference range were identified from a computerised hospital register of diabetic patients. Those with a recent severe illness, cardiac failure, abnormal liver function tests and symptomatic peripheral vascular disease were excluded on the basis that any of these conditions could cause a rise in plasma lactic acid levels. Age-matched patients with normal serum creatinine $<120$ $\mu \mathrm{mol} / 1(n=24)$ were then identified and invited to participate in the study. All subjects had been taking metformin for a minimum period of six months. Reference plasma lactic acid levels were determined using healthy nondiabetic controls, mean $1.742 \mu \mathrm{mol} / 1$ (SD 0.819).

Patient characteristics were recorded (table). A physical examination with particular regard to exclusion criteria was performed. Venous blood samples were withdrawn at $09.00 \mathrm{~h}$ following an overnight fast for urea while samples for estimation of electrolytes, serum creatinine, liver function tests, $\mathrm{HbAlc}$, serum B12 and plasma lactate were withdrawn prior to the patient's first dose of metformin.

Plasma lactate was measured using a Boehringer kit. The principle of this method is the oxidisation of L-lactate to pyruvate by lactate dehydrogenase, NADH is formed from NAD and acts as the indicator as it is proportional to the amount of lactate originally present. ${ }^{17}$ Normal plasma lactate levels (mean 1.742 
Table Characteristics and results of diabetic subjects with normal and raised creatinine

\begin{tabular}{|c|c|c|c|c|}
\hline & Normal & Creatinine $<120 \mu \mathrm{mol} / \mathrm{l}$ & Creatinine $>120 \mu \mathrm{mol} / \mathrm{l}$ & $p$-value ${ }^{\star}$ \\
\hline $\operatorname{Sex}(M: F)$ & $19: 15$ & $11: 14$ & $5: 12$ & \\
\hline Mean age (years) & 64.5 & 60.7 & 66.5 & NS \\
\hline Serum creatinine $(\mu \mathrm{mol} / \mathrm{l})$ & $94.2(10.3)$ & $101.7(11.6)$ & $132.2(9.5)$ & $<0.00001$ \\
\hline Plasma lactate $(\mathrm{mmol} / \mathrm{l})$ & $1.7(0.8)$ & $2.64(1.4)$ & $2.3(0.8)$ & NS \\
\hline Metformin dose (mg) & & $1846(616)$ & $1717(733)$ & NS \\
\hline BMI $\left(\mathrm{kg} \cdot \mathrm{m}^{-2}\right)$ & & $31.0(6.2)$ & $28.2(3.8)$ & NS \\
\hline $\mathrm{HbA}_{1 \mathrm{c}}$ & & $5.5(1.7)$ & $6.2(1.9)$ & NS \\
\hline Duration of diabetes (years) & & $6.5(5.3$ & $10.6(8.2)$ & NS \\
\hline Metformin use (years) & & $3.0(2.9)$ & $6.3(5.4)$ & $<0.02$ \\
\hline
\end{tabular}

Results expressed as means (standard deviation). NS=non-significant. ${ }^{\star}$ Comparing subjects with creatinine $<120$ with creatinine $>120$

\begin{tabular}{|l|}
\hline Learning points \\
\hline - metformin lowers blood glucose levels in \\
diabetic patients \\
- metformin does not cause hypoglycaemia \\
- lactic acidosis is a rare adverse event \\
- metformin increases lactic acid levels \\
\hline
\end{tabular}

$\mu \mathrm{mol} / 1$ (SD 0.819)) were established in agematched, healthy, non-diabetic volunteers.

Results are expressed as means with standard deviation. Comparisons between groups were performed by student's $t$-test with a p-value $<0.05$ considered significant.

\section{Results}

The mean dose of metformin was similar in both groups. All patients had a serum bicarbonate within the normal range. Patients with elevated serum creatinine had a longer duration of diabetes (10.6 vs 6.5 years, $\mathrm{p}=0.055)$, and longer use of metformin (6.3 vs 3.0 years, $\mathrm{p}<0.02$ ) compared with those with normal serum creatinine. Both groups taking metformin had significantly higher plasma lactate levels than the non-diabetic controls. No significant correlation between plasma lactate and serum creatinine was demonstrated $(r=-0.11,95 \%$ confidence limits -0.40 , $0.20)$.

No significant difference in serum B12 values was detected, although three very low B12 values were detected, of which two were from the group with elevated serum creatinine. Review of the patients' past medical histories and case notes did not reveal any illnesses associated with acidosis.

\section{Discussion}

The increased duration of diabetes and metformin use in the group with elevated creatinine levels may be expected to lead to high lactate levels, but this does not appear to have been the case. The low glycated haemoglobin levels in both groups would preclude high lactate as a result of uncontrolled diabetes.

1 Williams RH, Palmer JP. Farewell to phenformin for treating diabetes mellitus. Ann Intern Med 1975; 83: 567-68. 2 Nattrass M, Alberti KGMM. Biguanides. Diabetologia 1978; 14: $71-4$.
The effectiveness of metformin is mediated by increased peripheral glucose uptake ${ }^{18}$ and a reduction in hepatic glucose production by inhibition of hepatic gluconeogenesis. ${ }^{19} \mathrm{~A}$ consequence of these actions is to increase blood lactate levels in all patients on metformin. ${ }^{20}$ Our results indicate that a modest elevation of serum creatinine is not associated with increased plasma lactate levels. The reported cases of metformin-associated lactic acidosis have occurred mainly in patients with severe renal impairment, in whom reduced clearance of metformin has resulted in accumulation leading to hyperlactataemia. Metformin is normally rapidly eliminated, with a plasma half-life of $1.7-4.5 \mathrm{~h}^{21-23}$ This short elimination time suggests that accumulation of metformin may not occur with small elevations in serum creatinine and indeed, once daily dosing would guard against drug accumulation.

Monitoring of metformin-associated acidosis in different countries has shown that this remains an uncommon adverse effect over a 10 -year period in the UK $(1976-86)$ with only 0.027 cases per 1000 patient years (fatalities 0.017 per 1000 patient years). In Sweden, there were 0.024 per 1000 patient years from 1987-91 and it was reported that most of these cases were associated with cardiovascular or renal disease. ${ }^{24}$

If metformin were to be strictly prohibited in patients with renal impairment, the alternative therapies are alpha-glucosidase inhibitors, sulphonylureas or insulin, all of which also have adverse effects. There have been fatalities related to insulin-induced hypoglycaemia and there is increasing evidence that recurring hypoglycaemia causes cumulative brain dysfunction. ${ }^{25}$ Sulphonylurea drugs can also cause fatal hypoglycaemia ${ }^{26}$ and have been associated with haemopoietic disorders, also with fatal outcome.

Many patients with type 2 diabetes are obese. Alternative therapeutic agents such as sulphonylureas or insulin tend to aggravate obesity whereas metformin does not. Metformin is a valuable drug in the management of type 2 diabetes and its use in the context of mild renal impairment should be further evaluated.

\footnotetext{
3 Bailey CJ. The anti-hyperglycaemic action of metformin. $R$ Soc Med Int Congr Symp Ser 1985; 79: 17-26.

4 Bailey CJ. Metformin revisited: its actions and indications for use. Diabetic Med 1988; 5: 315-20.
} 
5 UK Prospective Study of Therapies of Maturity-onset Diabetes: 1 Effect of diet, sulphonylurea, insulin or biguanide therapy on fasting plasma glucose and body weight over one year. Multi-centre study. Diabetologia 1983; 24: $40-11$.

6 Sterne J, Junien JL. Metformin: pharmacological mechanisms of the anti-diabetic and antilipidec effects and clinical isms of the anti-diabetic and antilipidec effects and clinical consequ.

7 Hermann LS. Metformin a review of its pharmacological properties and therapeutic use. Diabetes Metab Rev 1979; 5: $233-45$

8 UK Prospective Diabetes Study 11. Reduction in HbAlc with basal insulin supplement, sulphonylurea or biguanide therapy in maturity onset diabetes. Diabetes 1985; 24: 793 8.

9 Wales JK. Treatment of the obese diabetic patient. In: Bjorntorp P, Cairelli M, Howard AN, eds. Recent advances in obesity research. London: Libby, 1980; pp 184-9.

10 Wu MS, Johnston P, Sheu WHH, et al. Effect of metformin on carbohydrate and lipoprotein metabolism in NIDDM patients. Diabetes Care 1990; 13: 1-8.

11 Chakrabarti R, Hocking ED, Fearnley GR. Fibrinolytic effect of metformin in coronary artery disease. Lancet 1965 ; effect of meto. $256-9$.

12 DeSilva SR, Shawe JE, Patel H, Cudworth AG. Plasma fibrinogen in diabetes mellitus. Diabete Metab 1979; 5: $201-6$.

13 Chan JC, Tomlinson B, Critchley JA, Cockram CS, Walden RJ. Metabolic and haemodynamic effects of metformin and glibenclamide in normotensive NIDDM patients. Diabetes Care 1993; 16: 1035-8.

14 Vague P, Juhan-Vague I, Alessi MC, Badier C, Valadier J. Metformin decreases the high plasminogen activator inhibition capacity, plasma insulin and triglyceride levels in nondiabetic obese subjects. Thromb Haemost 1987; 57: 326-8.

15 Robertson DA, Hale PJ, Natrass M. Macrovascular disease and hyperinsulinaemia. Clin Endocrinol Metab 1988; 2: and hyp.
16 Bailey CJ. Biguanides and NIDDM. Diabetes Care 1992; 15: $755-70$.

17 Noll F. Methods of enzymatic analysis. 2nd edn. HU Bergmeyer, p1475.

18 Prager R, Schernthaser G, Graf $H$. Effect of metformin on peripheral insulin sensitivity in non-insulin dependent peripheral insulin sensitivity in non-insulin dependent
diabetes mellitus. Diabete Metab 1986; 12: 346-50.

19 Gawler DJ, Milligan G, Houslay MD. Treatment of streptozocin rats with metformin restores the ability of streptozocin rats with metformin restores the ability of
insulin to inhibit adenylate cyclase activity. Biochem $\mathcal{F} 1988$;

20 Nattrass M, Todd PG, Hinks L, Lloyd B, Alberti KGMM. Comparative effects of phenformin, metformin, and glibenclamide on metabolic rhythms in maturity onset diabetes. Diabetologia 1977; 13: 145-52.

21 Noel M. Kinetic study of normal and sustained release dosage forms of metformin in normal subjects. Res Clin Forums 1979; 1: 35-50.

22 Pentikainen PJ, Neuivonen PJ, Penttila A. Pharmacokinetics of metformin after intravenous and oral administration to man. Eur f Clin Pharmacol 1979; 16: 195-202.

23 Tucker GT, Casey C, Phillips PJ, Connor H, Ward JD,

Woods HF. Metformin kinetics in healthy subjects and in patients with diabetes mellitus. Br $f$ Clin Pharmacol 1981; 12: $235-46$.

24 Wiholm BE, Myrhed M. Metformin associated lactic acidosis in Sweden 1977-1991. Eur f Clin Pharmacol 1993; 44: $589-91$

25 Langan SJ, Deary IJ, Hepburn DA, Frier BM. Cumulative cognitive impairment following recurrent severe hypoglycaemia in adult patients with insulin-treated diabetes mellitus. Diabetologia 1991; 34: 337-44.

26 Ferner RE, Neil HAW. Sulphonylureas and hypoglycaemia. BMF 1988; 296: 949-50.

Medical Anniversary

JAMES YOUNG SIMPSON, 7 JUNE 1811

(Sir) James Young Simpson (1811-70) was born in Bathgate, Scotland, the seventh son of a baker. He was educated in Edinburgh, where he qualified in medicine (1830), became an MD (1832), and was appointed professor of obstetrics (1839). He introduced chloroform for the management of labour (1847), and this was used by Queen Victoria (1853). 